\title{
Inmemoriam Dr Samten Tenzing
}

Badhu BP, Editor-in-Chief, Nepalese Journal of Ophthalmology

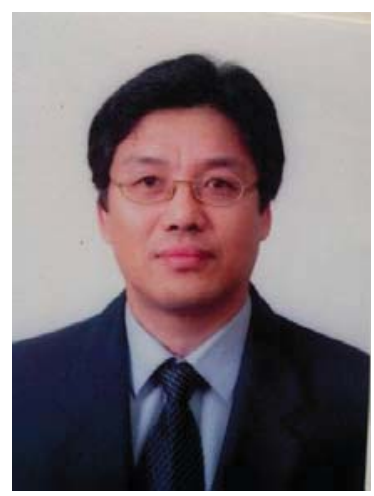

(1961-2014)

This issue of the journal is dedicated to Dr Samten Tenzing.

Born on 21st September 1961, Samten completed his secondary level education from the St Xavier's School, Kathmandu. He was awarded a Colombo Plan Scholarship in 1981 to undergo his MBBS at the Rajendra Medical College, Ranchi University, India after which he joined the same college as an Honorary Junior Resident House Physician in the Department of General Medicine. He returned home and served at the Bir Hospital as a House Surgeon from December 1989 till July 1990.

Dr Samten completed his MD (Ophthal) in 1995 from the Institute of Medicine, TU, Kathmandu, and completed one year of pediatric ophthalmology fellowship at British Columbia University, Vancouver, Canada. He joined the Lumbini Rana Ambika Eye Hospital Seva Foundation (USA) in Bhairahawa in July 1995 where he served as a Consultant Pediatric Ophthalmologist for several years.

It is with great sadness that I am writing this note in memory of Dr Samten Tenzing, an extraordinary ophthalmologist of our society who was very close to very many of our members and to his innumerable patients and who sadly passed away in September 2014.

Dr Samten Tenzing was a meticulous and laborious clinician and an honest, insightful and intelligent personality. I recall his contributions to the launching and subsequent upgrading of the Nepalese Journal of Ophthalmology. His loss has created a large gap in the functioning of the journal, but our respects and memory of Dr Samten will give us the strength required to bridge this gap, though not to completely fill it up.

When I first met with Samten 22 years ago, I realized that I could learn many things from him in addition to the subject of ophthalmology. His politeness, perseverance, unparalleled honesty, kindness and his spontaneous wish to help others without prejudice were perhaps the most prominent features that prevailed in his expres- 
sions and behavior. When I first went to meet him at his home, I noticed on a wall a small Godavari School certificate that had very simple language: "Certificate of a good boy conferred on SamtenTenzing". I realized that day that he had always been good. On my subsequent visit, I noticed a second similar certificate - issued to his son. He modestly smiled when I commented that he had a good successor.

We all are sad at the loss of Samten. I pray to the Almighty that He provide Dr Samten's family members with the strength to cope with this infinite loss.

Dr Samten will be remembered as a beautiful personality and an ophthalmologist of the highest professional quality and caliber. Let his memory motivate us all to continue the selfless eye care service that he always sought to provide.

Dr Samten was the youngest brother of Dr Chundak who expressed his feelings in the form of a poem as given below.

My youngest brother

Dr Chundak Tenzing, MD (Ophthalmology)

Director

Seva Foundation, USA

My youngest brother left us

Forever but

His presence

Is felt...

More than ever before

Wherever I see

And the closer I look

The clearer I see

His resemblance

When he was young

With his teenage son

My nephew

Who is with us

In health

And youthful bliss

Nourished

With a gift

Of sunshine

And rainfall

Of love to last

Till eternity 